\title{
Corpo e vida: a crítica de Hannah Arendt à modernidade científica
}

\section{| ${ }^{1}$ Wolfgang Heuer |}

Resumo: O presente artigo analisa as categorias de corpo e vida no pensamento de Hannah Arendt no contexto da crítica que a autora faz ao cientificismo moderno. Partindo da apresentação de alguns aspectos centrais da crítica arendtiana, passa-se a discutir em que medida essa crítica pode ser útil na discussão contemporânea acerca do biologismo e do mundo biotecnológico. Finalmente, tenta-se mostrar a radicalidade do pensamento da autora sobre o corpo e vida na sua relação com o conceito de corpo e vida da medicina tradicional chinesa.

> Palavras-chave: Hannah Arendt, corpo, vida, biotecnologias, medicina chinesa.
1 Professor de Ciência Política da Universidade Livre de Berlim. Endereço eletrônico: wolfgang. heuer@gmx.de

Recebido em: 28/08/2009. Aprovado em: 16/09/2009. 
O corpo e a vida encontram-se no centro das pesquisas que dominam nossos debates. Nas ciências culturais e naturais, assim como no debate público, trata-se de um culto do corpo, de "O mundo de corpos" (assim a exposição controversa do médico alemão Gunther von Hagens), da relação entre sujeito, corpo e poder e da definição de corpo e sexo no debate feminista ou de cyborgs, criaturas que consistem numa combinação híbrida de corpo e técnica (bios e techné). ${ }^{1}$ As pinturas corpo humano de Francis Bacon do focalizam a existência vulnerável do corpo e fazem de Bacon o pintor da corporeidade. ${ }^{2}$

Ao mesmo tempo, trata-se da vida. Vivemos já desde há muito uma mudança de paradigma. Não somente se trata da vida com respeito aos produtos saudáveis ou de uma maneira sadia de viver. Trata-se da vida na sua generalidade - desde a ecologia até a biotecnologia - e não somente da vida sob a perspectiva da saúde, mas também sob a perspectiva de usar energias biológicas e processos biológicos para a produção industrial. Para esse fim, deve ser decifrada não somente a vida humana, mas toda a vida. Assim surgiram as chamadas Life Sciences, que querem aperfeiçoar a vida interna e externa do homem. Em todos os campos, a vida obtém a atenção suprema: na pesquisa, em debates públicos controversos e na formação de valores morais, econômicos e políticos. A vida substitui esperanças religiosas de uma vida após a morte, assim como aspirações de objetivos superiores como revolução ou nação. É a mera vida onde se concentra toda a intensidade da experiência.

Então, a pergunta é: despedimo-nos assim de um mundo antigo e entramos em um outro completamente novo? Abandonamos agora o século XX das ideologias e guerras mundiais, da violência, dos voos altos da tecnologia e da exploração da natureza, para desenvolver uma identidade harmônica e ecológica? Não acredito. Não entramos em um mundo completamente novo, mas sim numa variante dentro do pensamento científico moderno - uma reorientação, que eu chamaria de uma volta de fora para dentro.

No século XX, corpo e vida foram definidos de maneira étnica e racista, e foram expostos à seleção estatal. No seu livro sobre o domínio totalitário, Hannah Arendt descreve a vida nua e desprotegida daqueles que perderam sua cidadania e que não tinham "direito de ter direitos". A vida nua se mostra para Arendt na atividade do trabalho, que obteve seu máximo desenvolvimento e reconhecimento na sociedade de trabalho e consumo do século XX. No seu livro A condição humana, Arendt dedica atenção particular a essa atividade e a descreve 
como atividade necessária, orientada à mera sustentação da vida, mas ao mesmo tempo como a atividade mais como uma atividade sem nenhuma referência ao mundo, interminável e por isso sem sentido. A vida transformou-se no maior de todos os bens, e a atividade adequada à vida, o trabalho, correspondeu de uma maneira indireta e estranha a uma forma de domínio sem nenhuma referência ao mundo e sem nenhum sentido: o domínio total. ${ }^{3}$

No século XX, a temática corpo/vida girou em torno de grupos específicos: a classe de trabalhadores, esportistas de elite, minorias étnicas, refugiados, cativos em campos. Esses grupos foram vistos de fora. No século XXI, a perspectiva se volta para dentro: agora se trata do corpo e da vida do indivíduo, da saúde e do lifestyle. Foucault examinou, nas suas considerações genealógicas sobre a modernidade, ambas as perspectivas: por um lado, a administração dos homens e a organização e gestão de populações em tempos modernos, por outro, a "governamentalidade", a interiorização do poder por autodominação e as tecnologias de aperfeiçoamento de si mesmo. ${ }^{4}$

No campo das ciências naturais também houve uma mudança. Depois da conquista do espaço e do universo, bem como do tempo e de energias cósmicas, realiza-se agora uma mudança para o desenvolvimento das potencialidades biotecnológicas; depois do universo, quer-se conquistar agora a própria vida. Arendt resumiu esta volta de fora para dentro na drástica frase: "depois da incapacidade de compreender o universo, voltou-se agora o caminho para dentro".

Gostaria de apresentar primeiramente alguns aspectos centrais da crítica de Hannah Arendt; na segunda parte vou discutir a questão, em que medida a crítica de Arendt pode ser útil em nossa discussão sobre o mundo biológico contemporâneo; na terceira parte, vou delinear as teses de Arendt sobre corpo e vida e tratar de evidenciar a radicalidade do pensamento dela, confrontando-o com o conceito de corpo e vida da medicina tradicional chinesa - um procedimento um pouco experimental.

\section{Crítica da alienação do mundo}

Depois de escrever seu livro sobre as origens do totalitarismo, Hannah Arendt se perguntou por que a tradição do pensamento europeu, com seus grandes pensadores, seus filósofos e cientistas políticos, não pôde oferecer nenhuma segurança contra o surgimento do domínio total e contra o Holocausto no 
século XX. Sua crítica foi radical: ela refutou o caráter apolítico da filosofia tradicional, que falava dos homens somente no singular (o homem) e que considerava mais importante a vita contemplativa que a vita activa. Ela refutou igualmente o pensamento político moderno, que baseia a política na distinção entre dominadores e dominados, que parte de uma identidade inaceitável entre dominação, poder e violência, e que submete a política a um pensamento em processos, ou na sua versão liberal, liga-a a um conceito de liberdade que corresponde a "estar livre de“. A ideia original de escrever uma breve introdução à política mostrou-se mais difícil do que o suposto, porque a crítica do pensamento político moderno deveria ser mais radical. Radical significa que a crítica do pensamento político teria de incluir também a crítica do pensamento em geral; ao mesmo tempo, a crítica da ação política na forma liberal, socialista ou marxista, teria de incluir uma pesquisa das atividades dos homens em geral. Por isso as perguntas fundamentais de Arendt eram: o que fazemos quando pensamos, e o que fazemos quando agimos - perguntas que procurou responder nos livros $A$ condição humana e $A$ vida do espírito.

No seu livro sobre o totalitarismo, Arendt examinou os elementos e as origens sociais e políticas do domínio total; através desta investigação descobriu, entretanto, conceitos sobre o pensamento e a ação, que poderiam da mesma forma ser incluídos a esses elementos e origens. Segundo Arendt, o conceito de identidade influenciou fatalmente a tradição europeia. Porque este "ser idêntico consigo mesmo" exclui tanto o diálogo interno, como precondição necessária a um julgamento independente - que Arendt considera indispensável para poder orientar-se em tempos de crise - bem como qualquer pluralidade: um desastre que conduziu a política ao racismo e ao nacional-socialismo. No pensamento totalitário, essa identidade, desprovida de qualquer conteúdo, é radicalizada em uma fusão do individuo coletivo com a ideologia.

A época moderna, declara Arendt em $A$ condição humana, se distingue sobretudo por uma "alienação [...] em seu duplo aspecto": "voo da terra para o universo e do mundo para dentro do homem." (ARENDT, 1993, p. 14).

São quatro os pontos principais que podem nos interessar, sobretudo no contexto da alienação do mundo: o afastamento do mundo, o pensamento em processos, o ethos da ação científica e a vida como o supremo de todos os bens. 
Quando Arendt começou a escrever seu livro A condição humana, começaram as viagens espaciais, um evento cuja importância, segundo ela, equivaleu à da fissão nuclear. Para Arendt, comentários como "o primeiro passo para libertar o homem de sua prisão na terra“ (ARENDT, 1993, p. 9), refletem essa fuga do mundo. Este afastamento do mundo começa na época moderna com a invenção do telescópio, continua com a descoberta e a conquista da terra, e se intensifica com os meios de transporte e sua velocidade progressiva. A velocidade conquista o espaço e ao mesmo tempo o faz desaparecer. Arendt explica:

A velocidade conquistou o espaço; e, ainda que este processo de conquista encontre seu limite na barreira inexpugnável da presença simultânea do mesmo corpo em dois lugares diferentes, eliminou a importância da distância, pois nenhuma parcela significante da vida humana - anos, meses ou mesmo semanas - é agora necessária para que se atinja qualquer ponto da terra. (ARENDT, 1993, p. 262).

Econclui: "qualquer diminuição de distâncias terrestres só pode ser conquistada ao preço de colocar-se uma distância definitiva entre o homem e a Terra, de aliená-lo do seu ambiente imediato e terreno" (ARENDT, 1993, p. 263).

Para Arendt, todos os processos subsequentes de alienação social, como expropriações de terras e acumulação de capital (a chamada "acumulação original" de Marx) são secundários em relação à primária "alienação da Terra, subjacente a toda evolução da ciência natural na era moderna" (ARENDT, 1993, p. 276). A essa alienação pertence a "matematificação" da realidade, através da qual "os fatos concretos [...] já não são mais formas ideais reveladas aos olhos da mente, mas o resultado de afastarem-se dos fenômenos os olhos da mente, não menos que os olhos do corpo, e de reduzirem-se todas as aparências pela força inerente à distância” (ARENDT, 1993, p. 279).

Aqui se mostra um fenômeno que parece paradoxo: o afastamento do mundo, que em meio a toda busca de dominação do mundo, conduz à desaparição do homem. Arendt questionou por ocasião do primeiro voo tripulado para a lua, em 1968: "Não resultou cada avanço da Ciência, desde a época de Copérnico, quase automaticamente em decréscimo de sua estatura?” (ARENDT, 1972, p. 338). E ela não somente constata que a estatura do homem desaparece, mas pior, que, na medida que seu poder cresce, sua "dignidade" (respeito de si mesmo) diminui (ARENDT, 2000, p. 395). 
Com a conquista e o afastamento do mundo nasce a alternação de triunfo e desespero que atravessa a época moderna. Diz Arendt:

Se colocarmos estes fatos em sua devida perspectiva histórica [...] é como se a desco-
berta de Galiléu comprovasse cabalmente que tanto o pior temor quanto a mais pre-
sunçosa esperança da especulação humana - o antigo temor de que nossos sentidos, os
próprios órgãos de que dispomos para receber a realidade, podem nos trair, e o desejo
arquimediano de um ponto fora da Terra a partir do qual o homem pudesse analisar
o mundo - só podiam realizar-se ao mesmo tempo, como se o desejo só pudesse ser
satisfeito se a realidade nos fugisse, e o temor só se consumasse quando compensado
pela aquisição de poderes supramundanos (ARENDT, 1993, p. 274).

Essa alternação se reflete nos movimentos pendulares entre períodos intermitentes de iluminismo e de romantismo. Aqueles que mais avançaram, cientistas como Schroedinger e Heisenberg, tiveram de constatar que haviam chegado a uma situação " na qual o homem perdeu a objetividade do mundo natural, de tal modo que, em sua perseguição da 'realidade objetiva', subitamente descobriu que sempre 'se confronta apenas consigo mesmo” (ARENDT, 1972, p. 340).

\section{Pensamento em processos}

O que determina o pensamento nas ideologias totalitárias já tem seus precursores no transcurso da Idade Moderna. Um pensamento em processos entra nas ciências naturais e históricas. "A mudança do 'por que' e do 'o que' para o 'como'", escreve Arendt,

implica que os verdadeiros objetos do conhecimento já não são coisas ou movimentos eternos, mas processos, e portanto o objeto da ciência já não é a natureza ou o universo, mas a história [...] Em lugar do conceito do Ser, encontramos agora o conceito de Processo. E, se é da natureza do Ser apresentar-se e revelar-se, é da natureza do Processo permanecer invisível. (ARENDT, 1993, p. 309-310).

No que concerne à fissão nuclear e ao uso pacífico ou belicoso da energia nuclear, os cientistas naturais não somente pensam em processos, mas desencadeiam tais processos eles mesmos; processos que finalmente não mais se detém mesmo diante da existência humana.

Para Arendt, que atribuiu tanta mundanidade e humanidade à ação espontânea e à liberdade de poder começar, a ação sob a forma dos atos dos cientistas naturais sofre uma virada surpreendente: seus "laboratórios cósmicos" eliminaram as fronteiras entre os homens e a natureza, submeteram o mundo em termos do espaço político às invenções das ciências naturais. Parece apropriado que "os feitos desses 
cientistas tenham assumido maior valor como notícia e maior importância política que os feitos administrativos e diplomáticos dos chamados estadistas" (ARENDT, 1993, p. 337). Daí resulta, para Arendt, que o realmente assustador da alienação do mundo consiste na "introdução do conceito de processo na atividade de fabricação" (1993: 314). Não o produto, mas o processo torna-se decisivo.

Para Arendt, a inversão de ação e trabalho é ao mesmo tempo essencial e inquietante: a ação livre da política é substituída pelo pensamento de processos da sociedade de trabalho, enquanto as atividades dos cientistas naturais no mundo de processos adotam o caráter de ação, do novo e do imprevisível.

\section{O ethos da ação científica}

Uma característica da experimentação é que ao imitar os processos naturais, o sentimento de fabricar algo natural se transforma em um sentimento de onipotência. Segundo Arendt (1993, p. 308), "todo cientista abordou a natureza, desde o início, do ponto de vista d'Aquele que a fez”. O traço de separação, como o chama Arendt, entre a época moderna e o mundo moderno, encontrase entre as ciências naturais e a ciência universal cósmica; a mudança ocorre com a invenção da bomba atômica. A ciência universal olha para a natureza da perspectiva do universo e não só elabora teorias sobre a relação entre massa e energia, mas também transforma realmente massa em energia e radiação em matéria. "Emprego deliberadamente a palavra 'criar' para indicar que estamos, na verdade, fazendo aquilo que todas as eras antes de nós julgaram ser a prerrogativa exclusiva da ação divina” (ARENDT, 1993, p. 281). A astrofísica substituiu a geofísica, e a ciência cósmica a ciência natural.

Mas já no seu tempo, Arendt constatou que essa ciência tem um limite existencial, que consiste na relação entre o tempo de vida humana e a distância cósmica. A busca do ponto arquimediano, com o qual se quer mover a terra e levantá-la dos seus ângulos, ameaça fracassar. Este impulso central da ciência cósmica, não exprime ele a híbris na fantasia do cientista natural? Não para Arendt: para ela faz parte do ethos, da moral da ciência, "que o que podemos descobrir devemos descobrir, o que podemos, devemos fazer." (ARENDT, 2000, p. 400). A própria pesquisa científica não é o problema, mas o autoentendimento da época moderna, que carrega a responsabilidade política do uso dos resultados científicos. Parece que alcançamos o fim das esperanças cósmicas, e por isso 
Arendt nutriu a esperança de que a perspectiva do mundo surgida daí tornarse-ia geocêntrica e antropomórfica uma vez, "que a terra e não o universo seria o centro e a pátria do homem mortal", e de que "sua mortalidade estaria entre as condiçôes elementares" (ARENDT, 2000, p. 402) da sua busca científica da verdade. Parece que Arendt não havia pressentido a virada biológica.

\section{A vida como o bem supremo}

Na análise de Arendt, a alienação concretamente experimentada na idade moderna conduz diretamente à filosofia da dúvida cartesiana. Segundo Arendt, quando no mundo exterior a essência e a aparência já não coincidem, resta somente o recuo a si mesmo, à reflexão do eu e à lógica do pensamento. A pesquisa do mundo não conduz de maneira alguma à certeza e à autoconfiança, mas, pelo contrário, à perda do mundo concreto, ou seja, da confiança nos sentidos, conduzindo a uma “desconfiança profunda do homem em si" (1993, p. 323). A antiguidade reagiu a uma profunda desconfiança do mundo com as filosofias estóicas e epicuristas e com hedonismo e cinismo. A eles correspondem no século XIX, segundo Arendt, o puritanismo, o sensualismo e o hedonismo. Para a filósofa, eles compartilham uma "intensificação da vida", uma "filosofia de vida na sua forma mais vulgar e menos crítica $[. .$.$] como se fosse lógico e natural considerar a vida como o mais$ alto bem" (ARENDT, 1993, p. 324-5).

O contexto desta filosofia de vida é para Arendt a substituição da visão mecanicista do mundo, com causa e efeito, pelo pensamento em processos da evolução orgânica. Agora é a vida que une o mundo interior e o exterior.

\section{A virada para dentro}

$\mathrm{Na}$ medida em que a pesquisa do universo encontrou suas fronteiras físicas, a pesquisa da vida pareceu tornar-se mais vantajosa. A biotecnologia moderna procura intervir no controle genético de processos biológicos, com métodos da engenharia genética e conhecimentos da biologia molecular, especialmente através da decifração do genoma. À parte da discussão sobre os perigos das mudanças biotecnológicas, nos interessa aqui, como na ciência natural tradicional, método e perspectiva do mundo. É evidente que a decodificação dos elementos constitutivos da vida e o reconhecimento de seus elementos e processos se baseiam na esperança de encontrar seu ponto arquimediano, para tornar-se criador da vida e formador 
do corpo. O americano Craig Venter, que decifrou o genoma humano no ano 2000, é o representante mais espetacular dessa visão de criador. Atualmente ele está pesquisando a criação de vida bacteriológica artificial, que poderia ser usada, por exemplo, na redução de dióxido de carbono. E obviamente, esta vida já está patenteada e, portanto, já é objeto de propriedade e comércio. Venter sonha com o aperfeiçoamento genético da inteligência humana, com organismos, "que não somente sobrevivem a radiações perigosas, mas que também podem viajar através do universo alegre e saudavelmente [...] e visa ao momento no qual será possível dar vida a um objeto inanimado. ${ }^{\text {5 }}$ Existe uma grande proximidade entre a pose de criador, a ficção científica e o hálito letal do uso militar. ${ }^{6}$

A pesquisa genética muda nossa imagem do corpo e da vida e com isso nossa imagem de saúde e doença. Já não é mais a medicina, mas sim a biotecnologia que pesquisa as doenças, e as fronteiras entre saúde e doença esfumam-se por trás de uma nova imagem do mecanismo biológico funcionando ou precisando de reparo. Quanto mais sabemos sobre a vida, mais facilmente podemos reconhecer ou profetizar defeitos no corpo individual com a ajuda de diagnose genética. $\mathrm{O}$ desempenho do corpo pode ser previsto e adequadamente utilizado.

Desde a perspectiva de Hannah Arendt, a estatura do homem se reduz mais uma vez: desta vez não por seu distanciamento da terra, senão, ao contrário, por seu vínculo ao corpo/vida. Esse vínculo não corresponde à ligação à pátria, esperada por Arendt, e tampouco liberta o homem para seu mundo no sentido da pluralidade, senão, ao contrário, determina suas ações. Porque agora, mais que nunca, sua ação gira em torno da vida, ou melhor, do seu corpo, cujos defeitos são conhecidos. Já não existe mais um "não saber", mas sim o "dever de saber".

Nasce o "cidadão biológico", que vê o mundo ecológico e biotecnológico através de uma rede de dados e critérios adequados. Ele esclarecido, na medida em que segue as regras de comportamento de uma vida saudável e responsável, regras de comportamento em um jargão popular médico-biotecnológico. Essas regras dependem da alta autoridade de uma multidão de especialistas do quotidiano, que substitui a autoridade dos antigos representantes de visões políticas. O cidadão biológico é democrático, não somente na medida em que participa dos debates éticos, mas também na medida em que assume o código de conduta adequado. Ele se mostra, assim, uma pessoa ativa e responsável. À parte disso, esse cidadão é biológico através das definiçôes de "autoridades políticas, pessoal médico, 
profissionais legais e penais, empregadores potenciais ou companhias asseguradoras - em termos de categorias tais como: doente crônico, deficiente, cego, surdo, pedófilo ou psicopata"; ou seja, biológico através de classificações que incluem e excluem (ROSE; NOVAS, 2005, p. 445). Assim nasce uma forma de biossociabilidade que afeta tanto a classificação social dos homens segundo categorias biológicas, quanto suas competências biossociais. Finalmente, o cidadão biológico desenvolve "biovalores" que giram em torno da saúde e da vida, e que, como se fossem os valores mais importantes, governam moral, economia e política. ${ }^{7}$

A vida já não só é o supremo dos bens, senão transforma-se ao mesmo tempo na própria prisão. Biologicamente e de maneira invariável, o homem é idêntico a si mesmo. O pathos do conhecimento e o da liberdade, que Arendt reconduz antropologicamente à natalidade, são desprezados pela biotecnologia reprodutiva. ${ }^{8}$ Liberdade e natalidade estão submetidas à planificação biológica. Se Arendt entende o naturalismo e a filosofia de vida como reação à desconfiança do mundo, então pode-se perguntar hoje, dada a penetração científica da nossa vida, a que formas de desconfiança isso conduz e quais serão as reações evocadas por elas.

O bioquímico Erwin Chargaff, um contemporâneo de Hannah Arendt, que participou de forma importante na decifração da estrutura do DNA, criticou em muitos artigos a insuficiência intelectual no seu campo científico entre os anos 60 e 80 do século XX. Criticou que, paradoxalmente, as Life Sciences não tivessem nenhuma definição da vida e não compreendessem as sutilezas da vida, que nunca se houvesse explicado tanto e se entendido tão pouco, que predominasse um reducionismo radical e uma mentalidade de brincadeira, que o conhecimento da alma houvesse sido perdido em favor de um conhecimento específico e que se subestimassem regularmente as consequências. Que valeria a pena estabelecer uma "Hall of Fame" de falsas previsões. ' Schroedinger e Heisenberg, como mencionado, também falaram sobre as fronteiras de sua disciplina. Assim estamos ansiosos para ouvir outros biotecnologistas criticos à parte de ostentadores como Venter.

Qual é a perspectiva alternativa de Hannah Arendt sobre corpo e vida?

\section{O pasmo atônito}

Em meio às suas reflexões sobre as mudanças drásticas da época moderna, Arendt descreve com ar casual a forma Socrática de pesquisa como o "choque da admiração, do espanto ante o milagre do Ser", que é a fonte de toda filosofia 
e cujo início e fim conduz a um "estado de mudez"10. Este pasmo se distingue

claramente da contemplação Platônica das ideias e, sobretudo do conceito moderno de "teoria" como um plano instrumental. Este antigo conceito de Ser perdeu-se com a ciência natural mas também com a filosofia moderna. A ênfase de Hannah Arendt na liberdade em forma da pluralidade e intersubjetividade entre os homens, não somente refuta sistemas de pensamento fechados, de lógica e de processos, mas também o individualismo e subjetivismo moderno. Para Arendt, o mundo não se divide em indivíduos, em "eu" e "eles", mas em relações interpessoais. A realidade se forma no contacto interpessoal, a liberdade somente existe na prática interpessoal assim como a política, a autoridade, o poder etc.

O conceito de corpo e vida de Arendt está definido por seu conceito de "mundo", ou seja, através de uma pluralidade que determina a condição humana, e sem a qual os homens se perdem em um abandono sem orientação. Para Arendt, a vida e sua atividade equivalente, o trabalho, pertencem à esfera das necessidades vegetativas, enquanto o sentido da vida somente se pode experimentar nas esferas da ação, da política e da cultura. A "mera" vida depende não somente da proteção de instituiçôes políticas e jurídicas, mas também da possibilidade de formar esse mundo entre nós, sem o qual os homens se reduzem a um estado puramente biológico, quase animalesco. $\mathrm{O}$ cuidado com o corpo e a vida equivale à esfera do privado, enquanto o mundo e os interesses comuns equivalem à esfera do público. Uma sociedade que somente se preocupa com o corpo e a vida acaba perdendo o mundo. Torna-se apolítica; e quando submete a política aos seus critérios, torna-se antipolítica.

Política e cultura são as esferas nas quais os homens expressam suas características humanas e se encontram. Somente agindo nessas esferas, eles são livres. O totalitarismo, com suas técnicas de desumanidade e extermínio, mostrou que a alternativa dos homens na sua existência terrena não é vida ou morte, mas humanidade ou desumanidade. A perda de direitos e o extermínio passo a passo dos homens mostraram à Arendt, que há algo pior que a morte, e que o inferno não se encontra além, mas aqui mesmo, no nosso mundo. Além disso, para Arendt não há um objetivo superior ao qual se pode submeter a política (por exemplo o homem novo, o progresso, a felicidade etc.), porque a definição de cada um desses conceitos restringe o mundo comum na sua pluralidade e abertura, diminui previamente as possibilidades políticas. Tampouco o aperfeiçoamento 
individual ou a arte de viver são de interesse político para Arendt. No encontro público os homens se descobrem através de uma perspectiva pluralista. Esta é a razão do ceticismo de Arendt em relação à psicanálise.

\section{O encontro com a China}

Queria dar uma olhada no pensamento tradicional chinês sobre corpo e vida contrastando-o com o pensamento europeu, para focalizar melhor a posição de Hannah Arendt. (Pode-se também entender a posição de Arendt como uma ponte entre o pensamento europeu e asiático). ${ }^{11}$

Até hoje a tradição filosófica europeia não aceita o pensamento chinês como filosofia, senão como uma forma de arte de viver que dificilmente se pode traduzir nas nossas línguas e no nosso pensamento. ${ }^{12}$ Sendo nossa língua e nossa forma de pensar cheias de categorias de distinções conceituais, como causa e efeito etc., torna-se difícil para nós até mesmo a tradução, e com isso o entendimento do pensamento chinês. $O$ pensador francês François Jullien descreveu durante os últimos anos em uma série de investigações, o entendimento completamente diferente dos conceitos de causa e efeito, moral, estética e tempo no pensamento tradicional chinês. Um dos seus últimos livros se ocupa de um conceito chinês usado com frequência: "nutrir sua própria vida“" (JULLIEN, 2005). Esta frase contém uma perspectiva do corpo e da vida, que é ao mesmo tempo acompanhada por uma outra visão da natureza e do homem e por uma instrução sobre como agir.

Queria somente mencionar alguns aspectos que se encontram no clássico chinês $O$ livro verdadeiro do país meridional das flores, do pensador taoísta Zhuangzi. Em relação ao corpo, ele escreve:

- O corpo não está definido como um conjunto anatômico e orgânico, mas como uma capacidade energética,

- Não existe separação entre corpo e espírito; nutrir sua própria vida nem é somente uma questão de contemplação espiritual (espírito), nem unicamente de alimentação biológica (corpo), e

- Não existe separação entre corpo e alma, entre soma e psique, porque não existe uma ontologia, nenhum "mundo de entidades específicas definíveis" (JULLIEN, 2006, p. 90); corpo e alma são formas de um ser vital constantemente atualizado. 
Em relação à vida, ele escreve:

- o conceito de doença aparece não como uma definição essencialA vida não se encontra no centro da atenção humana, mas é parte da unidade com o "tao" (uma forma de universo) e com o esquecimento de si mesmo;

- não tem nenhuma finalidade, consequentemente tampouco a finalidade da felicidade, mas sim a harmonia;

- não se trata da escolha de uma forma de viver, que é um tema constante desde Platão, mas sim da forma como se usa e se aumenta o capital de vida; e

- há que superar a vontade afetiva, o eu dominado pela vontade, e os conceitos de fim e finalidade, superando-se assim os potenciais de agressão e conflito.

Resumindo a diferença entre a China e o Ocidente:

- existe algo como a vivacidade, em contraste com as definições materialistas e idealistas de vida; não há essências, mas disposições;

- o mundo e a vida são considerados um "tornar-se", um "vir a ser", sem finalidade e fim;

- não há uma lógica de construção, mas um fluxo de vida;

- o conhecimento do ser não dá-se através de definições, mas sim pela sua utilização, pela experiência de ser;

- o comportamento orienta-se na oportunidade e na disponibilidade, mas como um obstáculo do desenvolvimento da vitalidade.

Essa descrição de corpo e vida não se baseia em conceitos e definições e não corresponde de nenhuma maneira à medicina ocidental. Nossa medicina, segundo Jullien, não tem em vista a saúde, mas "explicaçôes e tratamentos de doenças". É "extremamente intervencionista“. Palavras como "intervenção" e "operação" são "brutais até o trauma" e se encontram em flagrante contraste à medicina que regula e promove a saúde.

Nessa contraposição das perspectivas chinesa e europeia, aparecem características do nosso pensamento científico influenciadas pela herança da antiguidade grega: sua maneira de pesquisa ontológica e conceitual, seu foco em causa e efeito, sua orientação em objetivo e finalidade, a ausência da vida e a violência imanente.

Mostram-nos a crítica de Chargaff e a desilusão de Schroedinger e Heisenberg perante o fracasso da ciência natural moderna em encontrar a língua adequada para entender as "verdades", que esta maneira de pensar e falar não é adequada? 
E não somente no campo da ciência natural, mas no pensamento ocidental em geral? Michel Foucault constatou em 1978, durante uma viagem para o Japão e através da leitura intensa do zen-budismo, que, com o fim do imperialismo e a decadência da Europa no século XX, a filosofia europeia também chegou ao fim e careceu de uma reflexão. "Quando houver uma filosofia do futuro, ela terá de nascer consequentemente de encontros e confrontações entre Europa e NãoEuropa“" (JULLIEN, 2002, p. 37).

Arendt aparece no lugar de tais encontros mesmo sem realizá-los. ${ }^{13}$ Seu pensamento pertence, sem dúvida, à tradição ocidental, sobretudo sua preocupação com a política e sua paixão pela diferenciação, orientada na metodologia de Aristóteles. Não obstante, com seus conceitos de intersubjetividade, pluralidade e ação política sem finalidade e fim, ela desconstrói o pensamento de identidade que domina a filosofia e a política ocidental até hoje. É possível ver com clareza as semelhanças entre Arendt e o pensamento oriental tradicional: a recusa de uma ontologia, a ausência da separação entre espírito e corpo, a recusa em colocar a vida no centro das atençôes, a recusa de uma "arte de viver", a recusa da vontade individual etc. Não é a vida que se encontra no centro das relaçôes com a realidade, mas sim o mundo, o estar junto com os outros. A vida se satisfaz através do pensar e do agir, sem aspirar objetivos fora de si mesma.

\section{Referências}

ARENDT, H. A condição humana. Rio de Janeiro, Forense Universitária 1993.

. A conquista do espaço e a estatura humana. In: Entre o passado e o futuro [Between past and future). Tradução de Mauro W. B. Almeida. São Paulo: Perspectiva, 1972.

. Der archimedische Punkt [O ponto de Arquimedes]. In: . In der Gegenwart. Piper, 2000.

JULLIEN, François Le détour et l'accès. Stratégies du sens en Chine, en Grèce. Paris, 1995. Tradução alemã: Der Umweg über China. Ein Ortwechsel des Denkens, Berlin 2002. . Nourrir sa vie. In: . A L'écart du bonheur. Paris, 2005.

. Sein Leben nähren [Nourir sa vie]. Berlin, 2006.

ROSE, Nikolas; NOVAS, Carlos. Biological citizenship. In: ONG, Aihwa; COLIER, Stephen J, (Ed.). Global assamblages. Technology, politics, and ethics as anthropological problems. Oxford: Oxford, 2005. 
${ }^{1}$ Veja, por exemplo, as publicações de Judith Butler e de Anne Balsamo: Technologies of the Gendered Body: Reading Cyborg Women. Durham/NC 1996; Yvonne Bauer: Sexualität-Körper-Geschlecht. Befreiungsdiskurse und neue Technologien. Opladen 2003 (Sexualidade - corpo-gênero. Discursos de libertação e novas tecnologias).

${ }^{2}$ Com isso, Bacon reduz homem e gado ao estado elementar de criatura, liberando-os assim de cada história, cada movimento e cada sentido. Espaço e tempo são apenas vagas referências; tablados, jaulas, espelhos, alinhamentos e movimentos esfumam-se. Os numerosos Studies of the Human Body representam corpos, cuja presença humana, que atravessa a imagem, nada mais é que um "vestígio de memória”. Esses estudos não somente lembram os crimes cometidos contra a humanidade no século XX, como também chamam atenção para o corpo vulnerável em geral. Veja Wieland Schmied, Francis Bacon. Das Bewusstsein der Gewalt, München-New York 1996. (Francis Bacon. A consciência da violência).

${ }^{3}$ Agradeço a Simone Matthaei por essa observação e pela sugestão de abordar a questão.

${ }^{4}$ Veja a comparação das posições biopolíticas de Foucault e Arendt: Kathrin Braun, "Biopolitics and Temporality in Arendt and Foucault", in: Time \& Society, v. 16, n. 1, March 2007, p. 5-23.

${ }^{5}$ Lasst uns Gott spielen! Lebensfragen: J. Craig Venter programmiert die Zukunft. Von Jordan Mejias. Frankfurter Allgemeine, 31.08.2007, n. 202, p. 33 [Brincando de Deus! Questôes de vida: J. Craig Venter está programando o futuro].

${ }^{6}$ A novela de Michael Crichtons "Prey" trata do desenvolvimento descontrolado de microorganismos inteligentes para uso militar. Enquanto o trabalho de Venter ainda soa como ficção científica, a novela de Crichton já parece realista.

${ }^{7}$ É problemática a maneira como se constrói o conformismo da opinião pública, através de apelos em superlativos, proferidos periodicamente: "explosão de população", "degradação de florestas", "catástrofe climática”. Veja o texto do cientista climatólogico Stefan Rahmstorf, "Deutsche Medien betreiben Desinformation, Frankfurter Allgemeine 31. August 2007 [A mídia alemã produz desinformação] e a resposta do „cético do clima” Christian Bartsch, Wir müssen Urängste relativieren, Frankfurter Allgemeine, 5. September 2007 [Temos de relativizar medos fundamentais].

${ }^{8}$ Ludger Lütkehaus: "A biotecnologia reprodutiva cultiva a ênfase de um novo início cientifico e técnico e crê estabelecer novos inícios fundamentais através da revisão da natalidade, enquanto de fato despreza toda 'natureza', no seu sentido etimológico literal, mais alta representação do 'nativo'". Em: Damit ein Anfang sei... Hannah Arendt und die Debatte um Gentechnologie. Neue Zürcher Zeitung, 19.07.2003. [Para que haja um início... Hannah Arendt e a discussão sobre a engenharia genética].

${ }^{9}$ Veja Erwin Chargaff, Unbegreifliches Geheimnis. Wissenschaft als Kampf für und gegen die Natur, Neuwied, 1989 [Segredo incompreensivel. Ciência como luta pela e contra a natureza], sobretudo Wenig Lärm und Viel. Bemerkungen zur genetischen Bastelsucht [Pouco e muito barulho: Observações sobre a mania de bricolagem genética] e Über das Lebendige. Ausgewählte Essays, Stuttgart, 1993 [Sobre o vivo. Ensaios escolhidos].

${ }^{10}$ Vita activa, S. 295

${ }^{11}$ A conferência The thought of Hannah Arendt: Asian dialogues in the new century, com participantes de Hongkong, China, Taiwan e Japão, em dezembro de 2003 no Instituto Goethe de Hong Kong, tentou a construção de tal ponte. (organização: Wolfgang Heuer e Peter Baehr).

${ }^{12}$ A observação de Hegel, a filosofia chinesa seria uma leitura inocente e edificante, uma preparação 
para a meditação, ou somente apropriada para "den harten europäischen Verstand ... sich abzutun” [pôr de lado o duro intelecto europeu] reflete o desprezo europeu. W.F. Hegel: Vorlesungen zur Geschichte der Philosophie. Leipzig: G. Irrlitz, 1973, T. I, p. 136. [Palestras sobre a História da Filosofia].

${ }^{13}$ Somente em $A$ vida do espirito Arendt se ocupa do pensamento chinês no contexto de língua, metáfora e pensamento. 


\section{Abstract}

Body and life: Hannah Arendt's critique of scientific modernity

This paper analyzes the categories of body and life in Hannah Arendt's thought in the context of criticism that the author makes of modern scientific approach. From the presentation of some core aspects of Arendt's criticism, it discusses to what extent this criticism can be useful in contemporary discussion of biological and biotechnological world. Finally, it tries to show the radical thinking of the author about life in the body and its relationship to the concept of body and life of traditional Chinese medicine.

Key words: Hannah Arendt, body, life, biotechnologies, Chinese medicine. 